\title{
Colorectal Hamartoma
}

National Cancer Institute

\section{Source}

National Cancer Institute. Colorectal Hamartoma. NCI Thesaurus. Code C96474.

A non-neoplastic, hamartomatous polyp that arises from the colon and rectum. This group includes the juvenile polyp, Peutz-Jeghers polyp, and Cowden-associated polyp. 